\title{
ESTIMATION OF SOIL MOISTURE AND EARTH'S SURFACE TEMPERATURE USING LANDSAT-8 SATELLITE DATA
}

\author{
M. Entezari ${ }^{1} *$, A. Esmaeily ${ }^{1}$, S. Niazmardi ${ }^{1}$ \\ ${ }^{1}$ Department of Surveying Engineering, Graduate University of Advanced Technology, Kerman, Iran \\ Entezarimahmood1375@gmail.com, aliesmaeily@kgut.ac.ir, s.niazmardi@kgut.ac.ir
}

Commission VI, WG VI/4

KEY WORDS: Soil moisture, LST, Landsat-8, NDVI, GIS, Mashhad

\begin{abstract}
:
Soil moisture estimation is essential for optimal water and soil resources management. Surface soil moisture is an important variable in the natural water cycle, which plays an important role in the global equilibrium of water and energy due to its impact on hydrological, ecological and meteorological processes. Soil moisture changes due to the variability of soil characteristics, topography and vegetation in time and place. Soil moisture measurements are performed directly using in situ methods and indirect, by means of transfer functions or remote sensing. Since in-site measurements are usually costly and time-consuming in large areas, we can use methods such as remote sensing to estimate soil moisture at very large scales. The purpose of this study is to estimate soil moisture using surface temperature and vegetation indices for large areas. In this paper, ground temperature was calculated using Landsat- 8 thermal band for Mashhad city and was used to estimate the soil moisture content of the study area. The results showed that urban areas had the highest temperature and less humidity at the time of imaging. For this purpose, using the LANDSAT 8 images, the indices were extracted and validated with soil moisture data. In this research, the study area was described and then, using the extracted indices, the estimated model was obtained. The results showed that there is a good correlation between surface soil moisture content with LST and NDVI indices (95\%). The results of the verification of the soil moisture estimation model also showed that this model with a mean error of less than 0.001 can predict the surface moisture content, this small amount of error indicates the precision of the proposed model for estimating surface moisture.
\end{abstract}

\section{INRODUCTION}

Soil moisture, especially moisture content, plays a very important role in the management of water and soil resources. Soil moisture also plays an important role in the natural cycle of water, especially in the distribution of rainfall in form surface runoff and surface penetration, which is an important process after hydrological and geomorphological processes. Retrieving soil moisture data is important in various applications such as hydrology, climatology and soil sciences, ecology, and the exchange of energy and water flows. Precise Soil moisture is a key factor in these studies. Remote sensing techniques for soil moisture estimation include the use of visible, thermal infrared and active/passive microwave data so that each one has its own advantage and disadvantage. However, still, optical remote sensing is an effective technique for estimating soil moisture. This method requires the estimation of surface temperature and vegetation index for soil moisture calculation (Wang and $\mathrm{Qu}$, 2009).

Surface vegetation and Land surface temperature (LST) have a complex dependence on soil moisture. Carlson et al. (1994) and Gillies et al. (1997) showed that combining these two indicators can be used to estimate soil moisture with acceptable accuracy. Soil moisture changes have considerable effects on soil thermal properties. In other words, daily temperature variations are highly correlated with soil moisture content. Wang et al. (2007) and Engman,1985 combined soil moisture content with LST and NDVI indices which were derived from Landsat Surface Temperature and vegetation Indices respectively. The results showed a high correlation with ground-based observations. Based on these researches revealing close relation between NDVI and LST indices and soil moisture, the present study aimed to provide soil moisture estimation model using NDVI and LST indices for Mashhad city in Khorasan Razavi province.

\section{STUDY AREA}

The study area is Mashhad city of Khorasan Razavi province, located in the north-east of Iran with an area of $118854 \mathrm{~km}^{2}$, equivalent to seven percent of the country's total area (Figure 1). It is considered as the fifth largest province in the country and from the geographical point of view, this province located between $56^{\circ} 19^{\prime}$ to $61^{\circ} 16^{\prime}$ Eastern longitude and $33^{\circ} 52^{\prime}$ to $37^{\circ} 42^{\prime}$ northern latitude. The capital of this province is Mashhad, which is located in Kashfrood catchment between the Binalod mountain range and the Hezarmasjed mountain with an elevation of 1650 meters above sea level. The city of Mashhad has a temperate climate, but has warm and dry summers and experiences cold and humid winter. The average temperature of 15.7 degree per year and average precipitation of $212 \mathrm{~mm}$ per year were reported by National Climatology Centre.

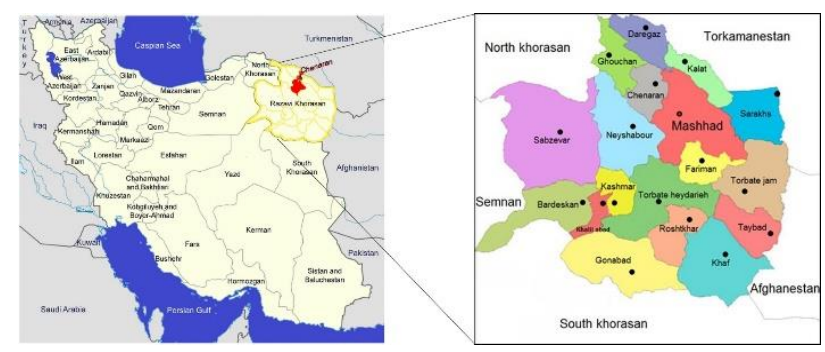

Figure 1. The study area, Mashhad City 


\section{METHODOLOGY}

\subsection{Data}

In this research, Landsat- 8 satellite data has been used due to the proper spatial resolution and cloud free coverage. The Landsat-8 image of March 15, 2019 was downloaded from the USGS site. Also, ENVI5.3 software was used as the main processing software and then ArcGIS 10.4 software was involved to produce final maps.

\subsection{Methods}

Figure 2 presents the Flowchart of this research. It illustrates different processing steps to achieve the soil moisture map.

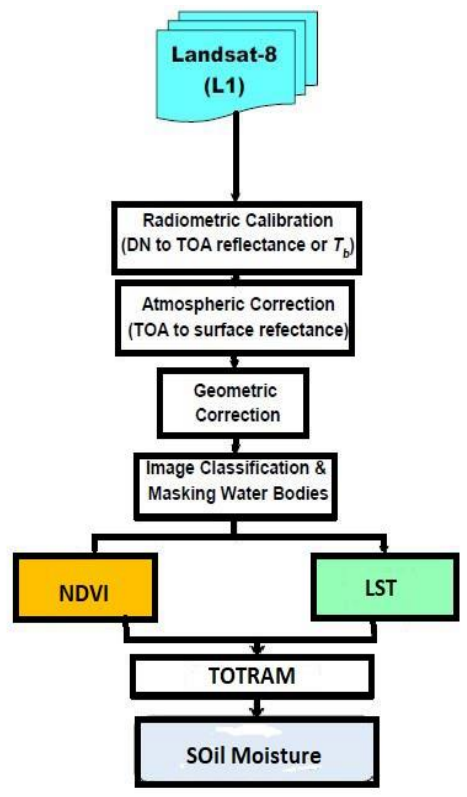

Figure 2. Flowchart of the used method

The first step to proceed consists to apply the Radiometric correction on the image data. The FLASH approach which uses the Meta Data file was applied to correct the bands, including multi-spectral and thermal bands. After this important correction, the geometric correction was applied as well. In addition, in order to avoid the effects of water body on soil moisture calculation, the water body was masked. The next steps are the NDVI and LST calculation.

3.2.1 Normalized Difference Vegetation Index: NDVI is an index to find out how much of the study area is covered by vegetation. The index gives a number between -1 and 1 representing the density of vegetation cover. Generally, the index approach to 1 , it means dense vegetation and less than zero represents water and cloud. equation (1) is used to calculate NDVI.

$$
\mathrm{NDVI}=\frac{\mathrm{NIR}-\mathrm{R}}{\mathrm{NIR}+\mathbb{R}}
$$

Where NDVI=Normalized difference Vegetation Index $\mathrm{R}=$ red band radiance $\mathrm{NIR}=$ infrared band radiance
The assumption is that the NDVI and the radiation power are constant for each pixel during the day. But moisture and rain can change radiation. Therefore, the highest amount of NDVI per day for the entire day is used to calculate the radiation power for each pixel.

3.2.2 Land Surface Temperature: Using the equations (2), the Land Surface Temperature was calculated. (Artis \& Camaham,1982)

$$
\text { LST }=\frac{T b}{1+\left(\lambda \times \frac{T b}{p}\right) \times \operatorname{Ln} \varepsilon}
$$

Where $\quad$ LST $=$ Land Surface Temperature

$\mathrm{Tb}=$ Brightness Temperature

$\lambda=$ wavelength of emitted radiance $(11.5 \mu \mathrm{m})$

$\mathrm{p}=1.438 \times 10^{-2} \mathrm{MK}$

$\varepsilon=$ Surface Emissivity

Figure 3 is the result of applying the equation 2 on Landsat- 8 image.

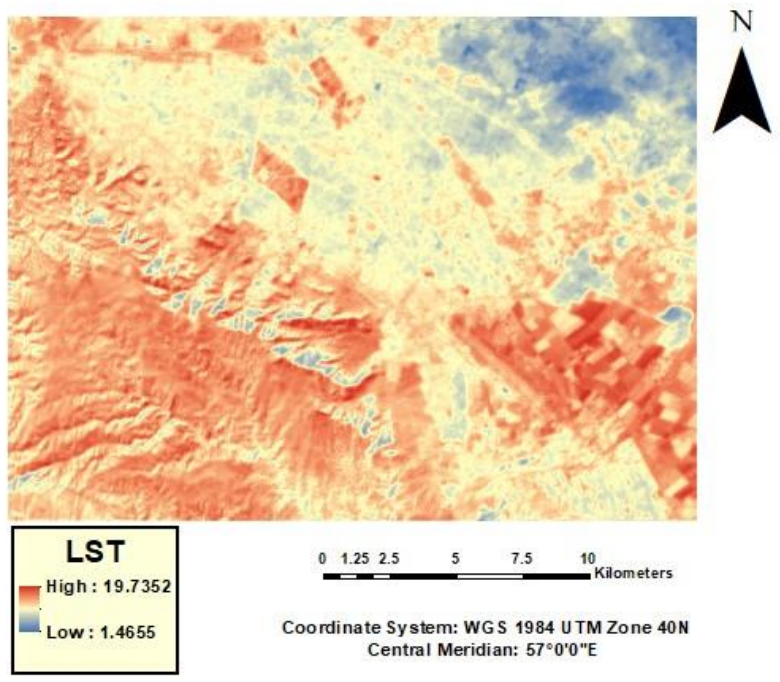

Figure 3. LST image calculated from Landsat-8 image data.

3.2.3 Soil moisture calculation: Based on Sadeghi et al. (2017), the soil moisture content was calculated using vegetation values and surface temperature by Thermal Optical Trapezoid Model (TOTRAM) which is generated using the equation (3).

$$
\mathrm{SM}=\frac{\left(\mathrm{i}_{\mathrm{d}}+\mathrm{s}_{\mathrm{d}}\right) \mathrm{NDVI}-\mathrm{LST}}{\left(\mathrm{i}_{\mathrm{d}}-\tilde{\mathrm{i}}_{\mathrm{W}}\right\}+\left[\mathrm{s}_{\mathrm{d}}-\mathrm{s}_{\mathrm{W}}\right) \mathrm{NDVI}}
$$

Where NDVI=Normalized difference Vegetation Index LST $=$ Land Surface Temperature

$$
\tilde{\mathrm{i}}_{\mathrm{d}}+\mathrm{s}_{\mathrm{d}}=\text { Dry Edge }
$$$$
i_{\mathrm{w}}+\mathrm{s}_{\mathrm{W}}=\text { Wet Edge }
$$

The interaction of vegetation covers and surface temperature in a 2D space created a graph illustrating the feature space of NDVI-LST (Figure 4). 


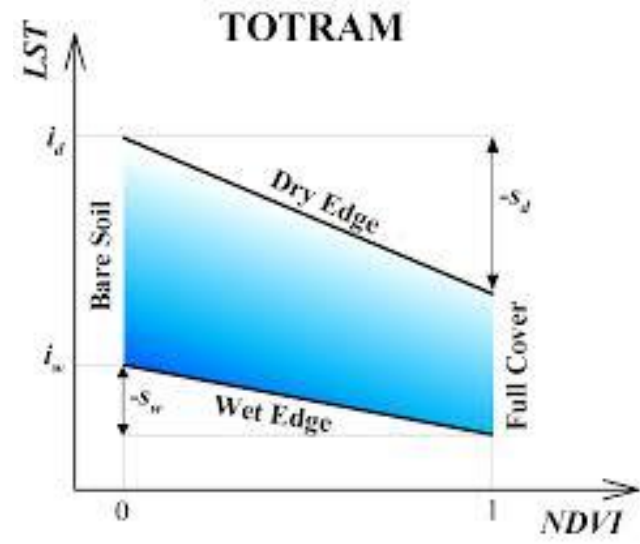

Figure 4. Thermal Optical Trapezoid Model.

In fact, Figure 5 represent the soil moisture situation based on the lowest and highest degree of NDVI and LST. Therefore, the equation (3) calculates the soil moisture regarding these two parameters and the results locates somewhere in the trapezoid. Lower location approaches to the wet edge and higher location shows dry edge.

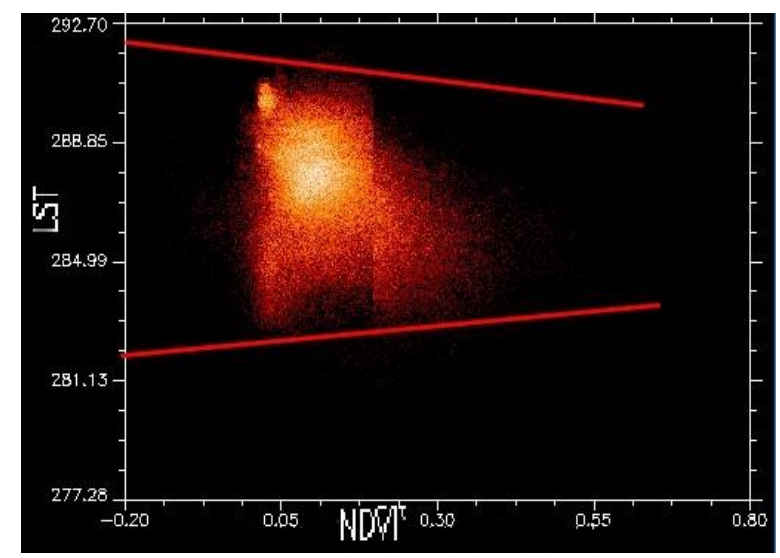

Figure 5. Optical and thermal trapezoidal model display for Mashhad city.

The highest and the lowest dry and wet edges were obtained based on Fig. 5 and the thermal optical trapezoidal model shown in Table 1.

\begin{tabular}{|c|c|c|c|c|}
\cline { 2 - 5 } \multicolumn{1}{c|}{} & \multicolumn{2}{c|}{ Dry Edge } & \multicolumn{2}{c|}{ Wet Edge } \\
\hline Model & $\mathrm{i}_{\mathrm{d}}$ & $\mathrm{S}_{\mathrm{d}}$ & $\mathrm{i}_{\mathrm{w}}$ & $\mathrm{S}_{\mathrm{w}}$ \\
\hline TOTRAM & 291.7 & -7.7 & 281.9 & -3.9 \\
\hline
\end{tabular}

Table 1. TOTRAM [Eq. (3)] parameters obtained for the Mashhad City and Landsat- 8 satellite data.

In this stage the soil moisture map was calculated using equation (3) and the final map is shown in Figure 6.

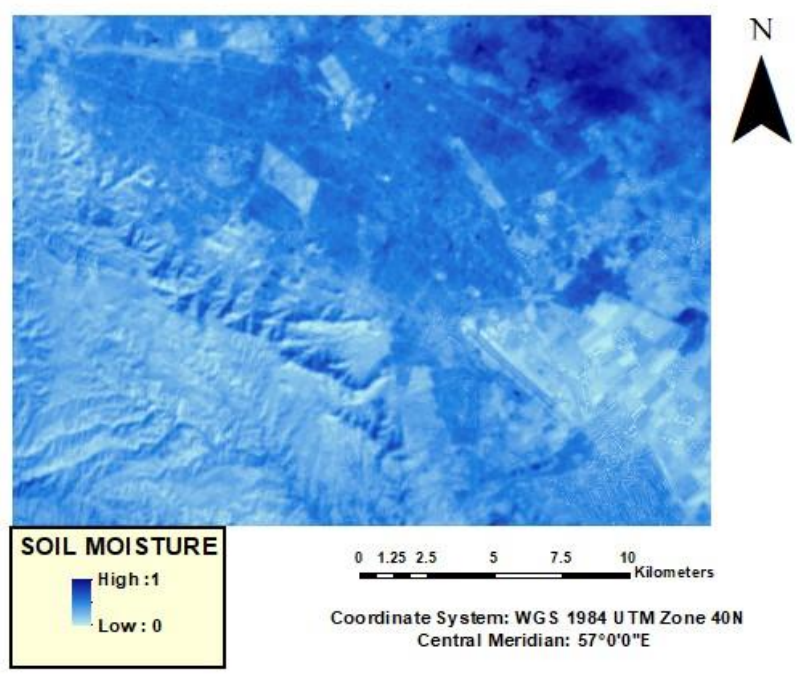

Figure 6. Soil moisture content map calculated by optical and trapezoidal model. The brown colour is showing the highest soil moisture and the blue colour shows lowest soil moisture.

Based on soil moisture estimation, using NDVI and LST indices, using SPSS software, a linear regression relationship will be obtained to improve the soil moisture estimation results and test them with the measured value.

\section{RESULTS AND DISCUSSION}

After calculating LST and NDVI indices, data were analyzed by Kolmogorov-Smirnov test (KS) using SPSS software. The results of this test are presented in Table 2.

\begin{tabular}{|c|c|c|c|}
\cline { 3 - 4 } \multicolumn{2}{c|}{} & NDVI & LST \\
\hline \multirow{2}{*}{ Normal Parameters } & Mean & 15 & 15 \\
\cline { 2 - 4 } & Std. Deviation & 0.05281 & $2.7872 \mathrm{e} 2$ \\
\hline \multirow{2}{*}{$\begin{array}{c}\text { Most Extreme } \\
\text { Differences }\end{array}$} & Absolute & 0.129 & $0.6219 \mathrm{e} 1$ \\
\cline { 2 - 4 } & Positive & 0.129 & 0.142 \\
\cline { 2 - 4 } & Negative & -0.098 & -0.214 \\
\hline \multicolumn{2}{|c|}{ Kolmogorov-Smirnov Z } & 0.499 & 0.827 \\
\hline \multicolumn{2}{|c|}{ Symp. Sig. (2-tailed) } & 0.965 & 0.500 \\
\hline
\end{tabular}

Table 2. Test distribution is normal and results of normalization test of indices used in soil moisture estimation model.

As shown in Table 2, the results of the Kolmogorov-Smirnov test (KS) indicate that data is normal. In the next step, to test the relationship between soil moisture content and the above indicators, the Pearson correlation test was carried out, the results of which are presented in Table 3 .

Soil moisture with NDVI index has a significant positive correlation at the 5\% level and Soil moisture with LST index has a significant negative correlation at the $1 \%$ level. Therefore, the results confirm the correlation of soil moisture content with vegetation index (NDVI) and surface temperature (LST) in our study area.

After calculating indices and their tests, in order to estimate soil moisture using NDVI and LST indices, SPSS software established a correlation between soil moisture content and the mentioned indices. The results are presented in Table $r$. 


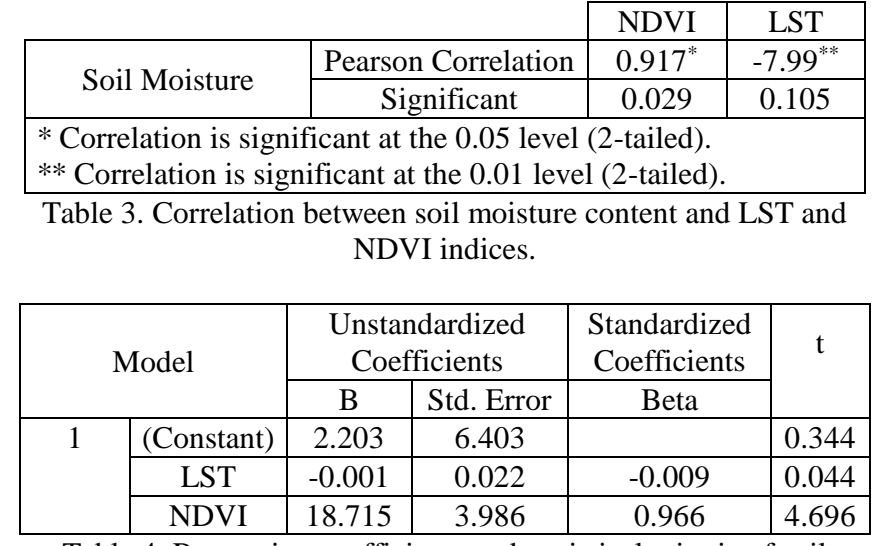

Table 4. Regression coefficients and statistical criteria of soil moisture estimation model.

\begin{tabular}{|c|c|c|c|c|}
\hline Model & $\mathrm{R}$ & R Square & $\begin{array}{c}\text { Adjusted R } \\
\text { Square }\end{array}$ & $\begin{array}{c}\text { Std. } \\
\text { Error of the } \\
\text { Estimate }\end{array}$ \\
\hline LST & 0.975 & 0.950 & 0.942 & 0.27513 \\
\hline NDVI & 0.972 \\
\hline
\end{tabular}

Table 5 shows the errors and statistical criteria between LST and NDVI.

Based on Table 5, the amount of R Square coefficient for the regression relationship was approximately 0.95 , which indicates an appropriate estimation of soil moisture by the model. In order to achieve a relationship between estimated soil moisture and listed indicators, linear regression was calculated using the Enter method (in SPSS software) between soil moisture content and NDVI and LST indices which is presented in equation (4).

$\mathrm{M}_{1}=18.715$ NDVI -0.001 LST +2.203

Using equation 4, soil moisture content can be estimated using the NDVI and LST indices that can easily be calculated through satellite imagery.

The ME value for the model equals to -0.001 and the RMSE value is 0.081 . The ME value indicates that the developed model estimates the soil moisture content 0.001 below its actual value.

Figure 7 shows the amount of estimated soil moisture using the suggested model for the measured data.

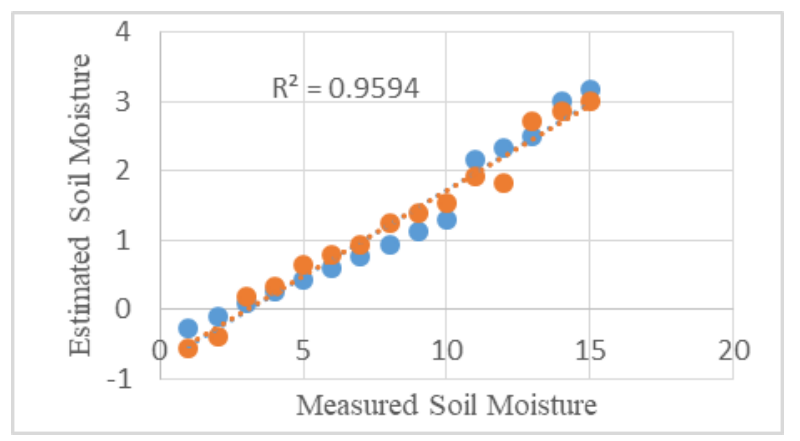

Figure 7. Distribution of soil moisture content measured and estimated from the application of the model.

\section{CONCLUSIONS}

The results obtained from the soil moisture estimation model in this paper showed that this model was able to estimate soil moisture in the shortest time in a large geographical area with acceptable accuracy. Also, the coefficient of determination 0.9594 was obtained which indicates the accuracy of the model obtained compared with the observed values. The model simulated by this model can predict $95 \%$ of soil moisture change in the area the soil moisture map obtained by this model is able to show good soil moisture variation within the studied area. This reflects the application of indicators and its importance in studies and estimation of soil moisture

\section{REFERENCES}

Artis, D.A. and Carnahan W.H., 1982. Survey of emissivity variability in thermography of urban areas. Remote Sensing Environ. 12, 313-329.

Carlson T, Gillies R, Perry E (1994). A method to make use of thermal 244 Front. Earth Sci. China 2009, 3(2): 237-247 infrared temperature and NDVI measurements to infer surface soil water content and fractional vegetation cover. Remote Sensing Reviews, 9: 161-173.

Engman E T, Chauhan N (1995). Status of microwave soil moisture measurements with remote sensing. Remote Sensing of Environment, 51, 189-198.

Sadeghi, M.; Babaeian, E.; Tulle, M.; Jones, S., 2017. The Optical Trapezoid Model: A Novel Approach to Remote Sensing of Soil Moisture Applied to Sentinel-2 and Landsat-8 Observations. Remote Sensing of Environment, 198:52-68.

Shafian, S.; Maas, S., 2015. Index of Soil Moisture Using Raw Landsat Image Digital Count Data in Texas High Plains. Remote Sensing, 7(3):2352-2372.

Sumintadireja, P.; Saepuloh, A.; Irwan, D.; Junursyah, L., 2011. Temporal Analysis of Visible-Thermal Infrared Band and Magneto telluric Method to Simulate a Geothermal Sitting at Mt. Ceramal West Java Indonesia.

Gillies R, Carlson T, Kustas W, Humes K (1997). A verification of the "triangle" method for obtaining surface soil water content and energyfluxes from remote measurements of the Normalized Difference Vegetation Index (NDVI) and surface radiant temperature. Int JRemote Sens, 18: 3145-3166.

Wang, Li.; Qu, J.; 2009. Satellite remote sensing applications for surface soil moisture monitoring: A review. Earth Sci. China 2009, 3(2): 237-247. 